\title{
ANALISIS PENGEMBANGAN INVESTASI PERALATAN RADIOLOGI DI RUMAH SAKIT UMUM RAJAWALI CITRA BANTUL YOGYAKARTA
}

\author{
Nur Wahyudi, Rosyidah \\ Fakultas Kesehatan Masyarakat, Universitas Ahmad Dahlan, Yogyakarta
}

\begin{abstract}
Background: Investment is basically an effort of investing resources (capital) in business. The radiology unit in Rajawali Citra Hospital is cooperatively performed by the third party or an investment from the third party. The investment of the radiology tools has been performed for more than 5 years, yet a reliability study from the investment has been conducted. This study aimed at assessing the reliability of developing the investment of radiology tools in Rajawali Citra Hospital over 5 years

Method: This study is a study with descriptive analysis method in quantitative and qualitative approach without using hypothesis. The subject of the study is parts of finance, radiology unit and medical support and financial balance of radiology in 2007 - 2011. The technique of data collection was interview and documentation of financial balance of the radiology unit. The data analysis was done descriptively by applying quantitative and qualitative analysis approach.

Result: The result of the study from the financial aspect indicated that payback period (3 years) 327 was quicker than the economical value of the tools (5 years), NPV $=$ Rp 5,252,878.3 investment was accepted because it resulted positive value, ARR $=150 \%$ investment was accepted because it provided more advantage than which has specified $100 \%$, IRR $=15,2 \%$ investment was accepted because the result was more than the interest $(10 \%), \mathrm{PI}=1,10$ the investment was accepted because the result was more than 1 .

Conclusion: From the whole aspect in the reliability assessment of the investment such as market aspect, technology, law, management and financial resulted in positive value to the investment development of the radiology tools.
\end{abstract}

Keywords: Investment, Reliability, Finance, Radiology.

\section{PENDAHULUAN}

Instalasi Radiologi di Rumah Sakit Rajawali Citra sendiri mulai ada sejak bulan November 2006. Pengadaan peralatan Radiologi itu sendiri dilakukan secara kerjasama operasional oleh pihak ketiga atau dengan istilah investasi dari pihak ketiga. Selama kurun waktu 5 tahun ini, belum pernah dilakukan kelayakan investasi dari pengadaan peralatan radiologi dari pihak investor. Berdasarkan tahun 2006-2011 statistik jumlah pasien di Rumah Sakit Rajawali Citra selalu mengalami kenaikan yang yang signifikan. Adanya rencana pengembangan unit radiologi untuk melakukan peremajaan peralatan yang di tujukan untuk meningkatkan kualitas pelayanan radiologi yang selama ini di pakai menarik peneliti untuk melakukan penelitian mengenai analisis pengembangan investasi peralatan radiologi di RS Rajawali Citra Bantul.

Investasi pada dasarnya merupakan usaha menanamkan sumber daya (modal) dalam kegiatan usaha/bisnis. Investasi biasanya ditanamkan pada sebuah proyek baru ataupun pengembangan proyek yang sudah berjalan. Kegiatan investasi ini ditujukan untuk memperoleh berbagai manfaat yang dapat berupa keuntungan finansial, seperti: laba, atau manfaat non finansial seperti : misi sosial, kecepatan 
dalam pelayanan, kelengkapan dalam hal pelayanan seperti dalam pemenuhan kebutuhan alat penunjang medis berupa peralatan radiologi.

Sugiharto (2002) ${ }^{1}$ menyatakan bahwa dalam melakukan investasi tersebut setiap perusahaan umumnya akan berusaha agar perluasannya dapat berkembang sesuai dengan tujuan perusahaan yaitu untuk mendapatkan laba sebesar besarnya untuk kelangsungan hidup perusahaan, sehingga seberapa lama pengembalian dana, yang ditanam di proyek tersebut menjadi sangat penting. Artinya, sebelum perusahaan menanamkan investasi untuk perluasan usaha baru, maka terlebih dahulu perlu diketahui apakah proyek atau investasi yang akan di lakukan dapat mengembalikan uang yang telah diinvestasikan dalam proyek tersebut dengan jangka waktu tertentu. Selain itu agar dapat melihat investasi yang di jalankan dapat memberikan keuntungan finansial seperti yang diharapkan.

Studi Kelayakan Bisnis (SKB) merupakan kegiatan yang dapat menjawab pertanyaan-pertanyaan tersebut pada Rumah Sakit Rajawali Citra karena SKB adalah suatu kegiatan yang mempelajari secara mendalam tentang suatu usaha atau bisnis yang akan dijalankan, dalam rangka menentukan layak atau tidak usaha tersebut dijalankan dengan menganalisis berbagai macam aspek.

\section{METODE PENELITIAN}

Penelitian ini merupakan penelitian dengan metode analisis deskriptif dengan pendekatan kuantitatif dan kualitatif tanpa menggunakan hipotesis. Pendekatan kuantitatif diperoleh dari biaya-biaya yang berhubungan dengan semua biaya opersional investasi pengadaan peralatan Radiologi di Rumah Sakit Umum Rajawali Citra selama kurun waktu 5 tahun.

Pendekatan kualitatif diperoleh dengan wawancara pada pihak-pihak yang terkait dengan radiologi. Subjek penelitian ini adalah manajemen khususnya bagian keuangan sebanyak 1 orang, kepala bagian radiologi sebanyak 1 orang dan wakil direktur atau kepala bidang penunjang medis di Rumah Sakit Umum Rajawali Citra terkait tata kelola unit radiologi serta pendapatan dan pengeluaran dan hasil keuntungan yang diperoleh unit radiologi selama kurun waktu 5 tahun, mulai bulan November 2006 sampai dengan bulan November 2011.

Variabel dalam penelitian ini yaitu biaya operasional peralatan radiologi yang terdiri dari gaji, invest, makan, penyusutan alat, bahan habis pakai, alat tulis kantor, biaya umum seperti telepon, listrik, air. Biaya investasi adalah biaya yang terdiri dari depresiasi gedung, depresiasi alat. Biaya pemeliharaan adalah biaya pemeliharaan gedung dan alat.

Pengolahan dan analisis data dilakukan dengan foto dokumentasi dan catatan dan hasilnya dikumpulkan, editing, dikelompokkan, penghitungan, pengolahan data, penyajian data dalam bentuk narasi dan interpretasi data dengan menghubungkan dengan teori yang ada. Alat Analisis kelayakan investasi:

\section{A. Metode PP (Payback Periode)}

Metode payback periode (PP) merupakan teknik penilaian terhadap jangka waktu (periode) pengembalian investasi suatu proyek atau usaha.

$$
\text { Payback Periode }=\frac{\text { Jumlah investasi }}{\text { Aliran kas bersih }} \times 12
$$

Kriteria pada Payback Period adalah : 
1) Jika Payback periodnya < waktu maksimum, maka usulan proyek atau usaha dapat di terima.

2) Jika Payback periodnya > waktu maksimum, maka usulan proyek tersebut di tolak.

\section{B. Metode ARR (Average Rate of Return)}

Merupakan cara untuk mengukur rata-rata pengembalian bunga dengan cara membandingkan antara rata-rata laba sebelum pajak EAT dengan ratarata investasi.

$$
\begin{aligned}
& \text { ARR }=\frac{\text { Rata }- \text { rata EAT }(\text { Average earning After Tax })}{\text { Rata }- \text { rata Investasi }(\text { Average Investemen })} \times 100 \% \\
& \text { Rata }- \text { rata EAT }=\frac{\text { Total EAT }}{\text { Umur Ekonomis }(\mathrm{n})} \\
& \text { Rata }- \text { rata EAT }=\frac{\text { Investasi }}{\text { Umur Ekonomis }(\mathrm{n})}
\end{aligned}
$$

\section{Metode NPV (Net Present Value)}

Merupakan metode analisis keuangan yang memperhatikan adanya perubahan nilai uang karena faktor waktu, proyeksi arus kas dapat dinilai sekarang (periode awal investasi) melalui pemotongan nilai dengan faktor pengurang yang di kaitkan dengan biaya modal (presentase bunga).

NPV = Total PV Aliran kas bersih - Total PV Investasi

Kriteria nilai NPV adalah :

1) Jika NPV $>0$ maka investasi diterima.

2) Jika NPV $<0$ maka investasi ditolak.

D. Metode IRR (Internal Rate of Return)

IRR adalah tingkat bunga yang akan diterima (PV Future procceds) sama dengan jumlah nilai sekarang dari pengeluaran modal (PV Capital Outlays).

$$
\mathrm{IRR}=\mathrm{P} 1-\mathrm{C} 1 \times \frac{\mathrm{P} 2-\mathrm{P} 1}{\mathrm{C} 2-\mathrm{C} 1}
$$

Keterangan :

$\mathrm{P} 1=$ Tingkat Suku bunga 1

P2 = Tingkat Suku bunga 2

$\mathrm{C} 1=\mathrm{NPV} 1$

C2 = NPV 2

Kriteria penilaian IRR adalah jika IRR $>$ dari suku bunga yang telah ditetapkan, maka investasi diterima, jika $\mathrm{IRR}<$ dari suku bunga yang telah ditetapkan, maka investasi ditolak.

\section{E. Metode PI (Profitabilitas Indeks)}

Indeks profitabilitas adalah rasio atau perbandingan antara jumlah nilai arus kas selama umur ekonomisnya dan pengeluaran awal proyek.

$$
\mathrm{PI}=\frac{\text { Total PV Kas Bersih }}{\text { Total Investasi }}
$$

Kriteria untuk Profitabilitas Indeks yaitu Proyek dinilai layak jika PI> atau $=1,00$, sebaliknya dinilai tidak layak jika $\mathrm{PI}<1,00$. 


\section{HASIL PENELITIAN DAN PEMBAHASAN}

A. Hasil Penelitian

1) Metode Payback Periode

Berdasarkan penelusuran data yang diperoleh di bagian keuangan didapatkan data sebagai berikut:

Tabel.1 Pendapatan Bersih Setelah di Kurangi Pajak

\begin{tabular}{ccccccc}
\hline No & Tahun & $\begin{array}{c}\text { Total Penda- } \\
\text { patan }\end{array}$ & $\begin{array}{c}\text { Total } \\
\text { Penge- } \\
\text { luaran }\end{array}$ & $\begin{array}{c}\text { Sisa inves- } \\
\text { tasi }\end{array}$ & $\begin{array}{c}\text { Pajak } 10 \\
\%\end{array}$ & $\begin{array}{c}\text { Laba ber- } \\
\text { sh }\end{array}$ \\
\hline 1 & 2007 & 26.070 .000 & 19.356 .500 & 6.713 .500 & 671.350 & 6.042 .150 \\
\hline 2 & 2008 & 46.834 .000 & 35.695 .500 & 11.138 .500 & 1.113 .850 & 10.024 .650 \\
\hline 3 & 2009 & 67.132 .000 & 50.770 .000 & 16.354 .200 & 1.635 .420 & 14.718 .780 \\
\hline 4 & 2010 & 90.222 .000 & 66.735 .600 & 23.486 .400 & 2.348 .640 & 21.137 .760 \\
\hline 5 & 2011 & 119.368 .500 & 90.196 .250 & 29.172 .250 & 2.917 .225 & 26.255 .025 \\
\hline Jumlah & 349.626 .500 & 262.753 .850 & 86.872 .650 & 8.687 .265 & 78.185 .385 \\
\hline
\end{tabular}

Sumber : Bagian Keuangan RS Rajawali Citra

Berdasarkan tabel pendapatan bersih tahunan di atas dapat kita hitung payback periode sebagai berikut:

Total investasi

:Rp.50.000.000

Pendapatan bersih tahun ke $1 \quad$ :Rp. 6.042 .150

Rp. 43.957 .850

Pendapatan bersih tahun ke 2 :Rp. 10.024 .650 -

Rp. 33.933 .200

Pendapatan bersih tahun ke $3 \quad$ :Rp. 14.718 .780 -

Rp. 19.214 .420

Di karenakan pendapatan bersih untuk tahun ke 4 melampaui sisa investasi dari tahun ketiga maka dapat kita hitung sebagai berikut:

$$
\begin{aligned}
\text { Payback Periode } & =\frac{\text { Rp. } 19.214 .420}{\text { Rp. } 21.137 .760} \times 12 \times 30 \text { hari } \\
& =327,2 \text { hari }
\end{aligned}
$$

Jadi, berdasarkan perhitungan payback periodenya dapat di simpulkan bahwa modal akan kembali dalam jangka waktu 3 tahun 327 hari karena payback periodenya lebih cepat dari nilai ekonomisnya maka investasi peralatan radiologi layak dan dapat dikembangkan.

\section{2) Metode ARR (Average Rate of Return)}

Metode ini digunakan untuk mengukur berapa tingkat keuntungan ratarata yang diperoleh dari suatu investasi.

$$
\begin{aligned}
\text { Rata - rata EAT } & =\frac{\text { Total EAT }}{\text { Umur Ekonomis }} \\
& =\frac{\text { Rp. } 78.185 .385}{5} \\
& =\operatorname{Rp} \cdot 15.637 .077
\end{aligned}
$$




$$
\begin{aligned}
\text { Rata }- \text { rata Investasi } & =\frac{\text { Investasi }}{\text { Umur Ekonomis }} \\
& =\frac{\text { Rp. } 50.000 .000}{5} \\
& =\text { Rp. } 10.000 .000 \\
\text { ARR } & =\frac{\text { Rata }- \text { rata EAT }}{\text { Rata }- \text { rata Investasi }} \times 100 \% \\
& =\frac{15.637 .077}{10.000 .000} \\
& =150 \%
\end{aligned}
$$

Berdasarkan data di atas, hasil ARR nya $>$ dari tingkat keuntungan yang diisyaratkan yaitu sebesar $100 \%$, maka proyek ini diterima.

\section{3) Metode NPV (Net Present Value)}

Metode ini digunakan untuk mengukur kelayakan investasi, di mana seluruh proyeksi arus kas bersih di masa depan harus dinyatakan ke dalam nilai sekarang yang dikonversikan dengan tingkat suku bunga atau discount faktor. Perhitungan Net Present Value merupakan perkalian antara Net Cash Value atau pendapatan bersih setelah pajak dikalikan dengan discount faktor. Discount faktor yang dipakai oleh peneliti disesuaikan dengan tingkat suku bunga deposito saat ini yaitu 10\%. Adapun perhitungan dapat kita lihat dalam tabel berikut ini.

Tabel. 2 Perhitungan Net Present Value dengan Discount Factor $10 \%$

\begin{tabular}{ccccc}
\hline Tahun ke-n & $\begin{array}{c}\text { Total pendapatan } \\
\text { bersih }\end{array}$ & DF 10\% & Investasi & NPV \\
\hline 0 & -50.000 .000 & 1 & -50.000 .000 & - \\
\hline 1 & 6.042 .150 & 0,909 & & $5.492 .314,4$ \\
\hline 2 & 10.024 .650 & 0,826 & $8.280 .360,9$ \\
\hline 3 & 14.718 .780 & 0,751 & 11.053 .803 \\
\hline 4 & 21.137 .760 & 0,683 & 14.437 .090 \\
\hline 5 & 26.255 .025 & 0,609 & 15.989 .310 \\
\hline Total & & & 55.252 .878 .3 \\
\hline NPV & & & 5.252 .878 .3 \\
\hline
\end{tabular}

Sumber : Bagian Keuangan RSU Rajawali Citra

Berdasarkan perhitungan di atas, NPV nya bernilai positif dan nilainya > 0 , maka rencana pengembangan investasi yang akan dilakukan layak untuk dilakukan.

\section{4) Metode IRR (Internale Rate of Return)}

Metode ini digunakan untuk mengukur berapa tingkat pengembalian intern yang diperoleh dari suatu investasi. Berikut ini tabel yang menunjukkan hasil IRR dan PV AKB kedua dengan DF sebesar $40 \%$. 
Tabel 3. Hasil IRR dan PV AKB Kedua dengan DF 40\%

\begin{tabular}{llllll}
\hline Tahun & $\begin{array}{c}\text { Aliran Kas } \\
\text { Bersih }\end{array}$ & $\begin{array}{c}\text { Bunga } \\
10 \% \text { DF }\end{array}$ & PV Kas Bersih & $\begin{array}{c}\text { Bunga } \\
40 \% \text { DF }\end{array}$ & $\begin{array}{c}\text { PV Kas Ber- } \\
\text { sih }\end{array}$ \\
\hline 2007 & 6.042 .150 & 0,909 & $5.492 .314,4$ & 0,714 & $4.314 .095,1$ \\
\hline 2008 & 10.024 .650 & 0,826 & $8.280 .360,9$ & 0,510 & $5.112 .571,5$ \\
\hline 2009 & 14.718 .780 & 0,751 & 11.053 .803 & 0,364 & $5.357 .635,9$ \\
\hline 2010 & 21.137 .760 & 0,683 & 14.437 .090 & 0,260 & $5.495 .817,6$ \\
\hline 2011 & 26.255 .025 & 0,609 & 15.989 .310 & 0,186 & $4.883 .434,7$ \\
\hline
\end{tabular}

Total PV Proceeds

$55.252 .878,3$

25.163.554,8

$$
\begin{aligned}
& \text { NPV } 1=\mathrm{C} 1=\text { Total PV } 1-\text { Total Investement } \\
& =55.252 .878,3-50.000 .000 \\
& =5.252 .878,3 \\
& \text { NPV } 2=\mathrm{C} 2=\text { Total PV } 2-\text { Total Investement } \\
& =25.163 .554,8-50.000 .000 \\
& =-24.836 .445,2 \\
& \mathrm{P} 1=10 \%=0,1 \\
& \mathrm{P} 2=40 \%=0,4 \\
& \mathrm{IRR}=\mathrm{P} 1-\mathrm{C} 1 \times \frac{\mathrm{P} 2-\mathrm{P} 1}{\mathrm{C} 2-\mathrm{C} 1} \\
& \mathrm{IRR}=0,1-5.252 .878,3 \times \frac{0,4-0,1}{-24.836 .445,2-5.252 .878,3} \\
& \operatorname{IRR}=0,1+\frac{1.575 .863,5}{30.089 \cdot 324,3} \\
& \mathrm{IRR}=0,1+0,0523 \\
& \text { IRR }=0,1523 \times 100 \% \\
& \text { IRR }=15,2 \%
\end{aligned}
$$

Nilai IRR yang diperoleh adalah sebesar 15,2 \% lebih besar dari bunga deposito sebesar $10 \%$ maka IRR diterima.

\section{5) Metode PI (Profitabilitas Indeks)}

Metode ini digunakan untuk membandingkan nilai sekarang dari arus kas bersih terhadap pengeluaran awalanya.

$$
\begin{aligned}
& P=\frac{\text { Total } P V \text { Bersih }}{\text { Total Investasi }} \\
& P=\frac{55.252 .878,3}{50.000 .000} \\
& P=1,10
\end{aligned}
$$

Berdasarkan penelusuran Profitabilitas Indeks hasilnya adalah 1,10. Berarti investasi peralatan radiologi di RSU Rajawali Citra layak dilakukan dan dikembangkan, karena syarat $\mathrm{PI}$ di terima adalah $>1$.

\section{B. Pembahasan}


Berdasarkan informasi dari pihak investor, unit radiologi di bangun dengan total investasi kurang lebih Rp. 50.000.000,00. Nilai itu berasal dari pembelian pesawat rontgen dan perlengkapanya serta pembuatan renovasi ruang radiologi. Berdasarkan informasi pihak investor nilai ekonomis dari peralatan radiologi itu di perkirakan sekitar 5 tahun. Untuk menilai kelayakan investasi yang telah dilakukan dapat di ketahui dengan beberapa metode antara lain :

\section{1) Metode Payback Periode (PP)}

Hasil perhitungan payback sendiri di peroleh hasil bahwa modal akan kembali pada waktu 3 tahun 327 hari lebih cepat dari umur ekonomis dari peralatan yang diinvestasikan yaitu 5 tahun. Hal ini bisa menjadi acuan bahwa investasi yang di lakukan layak untuk dikembangkan.

Suatu usulan proyek investasi akan diterima jika periode pengembalian yang dihasilkan lebih cepat dari yang diisyaratkan. Sebaliknya, jika periode pengembalian yang dihasilkan lebih lama dari yang di isyaratkan, maka usulan proyek investasi tersebut ditolak. ${ }^{2}$

2) Metode Net Presen Value (NPV)

Metode ini di gunakan untuk menilai masa sekarang. Di dapat nilai sebesar 5.252.878,3, karena NPV menunjukkan nilai yang positif atau lebih dari 0 maka dapat di simpulkan bahwa proyek tersebut layak untuk dilaksanakan.

Keputusan tentang apakah suatu usulan proyek investasi diterima atau ditolak ditentuakn oleh nilai NPVnya. Jika NPV positif, artinya dana yang diinvestasikan dalam proyek tersebut dapat menghasilkan PV arus kas lebih tinggi dari PV investasi awal. Sebaliknya, jika NPV negatif artinya dana yang diinvestasikan dalam proyek tersebut dapat menghasilkan PV arus kas yang lebih rendah dari nilai sekarang investasi awal. Dengan demikian, suatu usulan proyek investasi diterima jika NPV-nya lebih besar dari nol. Sebaliknya, suatu usulan proyek ditolak jika NPV-nya lebih kecil dari nol. ${ }^{2}$

\section{3) Metode Internal Rate of Return (IRR)}

Internal Rate of Return dipergunakan untuk mengevaluasi profitabilitas rencana investasi dengan memperhatikan nilai uang. Setelah menghitung IRR dengan suku bunga $10 \%$ di peroleh hasil IRR sebesar $15,2 \%$. Dengan demikian berdasarkan nilai IRR yang lebih tinggi dari tingkat suku bunga menjadi dasar bahwa investasi tersebut layak untuk di kembangkan.

Suatu usulan proyek investasi diterima jika IRR-nya lebih tinggi atau sama dengan biaya modal atau tingkat suku bunga atau IRR. Sebaliknya, suatu usulan proyek invetasi ditolak jika IRR-nya lebih rendah dari biaya modal/tingkat suku bunga RRR (Halim, 2003). ${ }^{3}$

\section{4) Metode Average Rate of Return (ARR)}

Metode ini di gunakan untuk mengukur berapa tingkat keuntungan ratarata yang di peroleh dari suatu investasi. Setelah di lakukan perhitungan dari data yang ada di peroleh hasil ARR sebesar $150 \%$. Berdasarkan hasil tersebut dapat menggambarkan bahwa investasi itu layak untuk di kembangkan karena tingkat keuntungan yang diperoleh melebihi tingkat 
keuntungan sebesar $100 \%$, maka investasi ini diterima ata layak di kembangkan.

5) Metode Profitabilitas Indeks (PI)

Metode ini digunakan untuk membandingkan nilai sekarang dari arus kas bersih terhadap pengeluaran awalnya. Berdasarkan perhitungan data yang ada telah diperoleh hasil profitabilitas indeks sebesar 1,10 karena profitabilitas indeks lebih dari 1 maka investasi yang di lakukan layak untuk dikembangkan. Suatu investasi akan di terima jika indeks profitabilitasnya lebih dari satu, dan sebaliknya akan ditolak jika indeks profitabilitasnya lebih kecil dari satu. ${ }^{2}$

Hasil pembahasan semua aspek dalam penentuan kelayakan investasi yang di lakukan di Rumah Sakit Umum Rajawali Citra telah menunjukkan hasil yang positif untuk pengembangan unit radiologi. Di harapkan manajemen dan investor dapat mengembangkan peralatan radiologi sesuai dengan perkembangan peralatan kesehatan khususnya di bidang radiologi agar tidak tertinggal oleh kemajuan teknologi dan keinginan dari pasar yang semakin bersaing. Namun penulis berharap agar Rumah Sakit Umum Rajawali Citra tidak hanya mengejar keuntungan saja dalam pelayanan kesehatan namun di dasarkan dengan investasi dalam perspektif Al-Quran.

\section{SIMPULAN DAN SARAN}

\section{A. Simpulan}

Berdasarkan hasil pengumpulan data dan pembahasan yang telah dilakukan penulis, maka penulis menyimpulkan bahwa :

1) Berdasarkan keseluruhan aspek yang di teliti, yaitu aspek pasar dan pemasaran, aspek teknik produksi dan teknologis, aspek manajemen dan sumber daya manusia, aspek hukum dan legalitas, serta aspek keuangan dan ekonomi menunjukkan bahwa investasi peralatan radiologi di RSU Rajawali Citra layak di lakukan dan dikembangkan.

2) Rencana Pengembangan investasi peralatan radiologi di RSU Rajawali Citra yang akan dilakukan di kaji dengan 5 metode kelayakan investasi dengan hasil sebagai berikut :

a) Metode payback period menjukkan bahwa waktu yang di perlukan untuk menutup investasi sebesar Rp. 50.000 .000 adalah 3 tahun 327 hari.

b) Metode ARR (Average Rate Of Return) menunjukkan bahwa tingkat keuntungan rata-rata yang di peroleh sebesar $150 \%$.

c) Metode NPV (Net Present value) di dapat dilai yang positif sebesar Rp. 5.252.878,30.

d) Metode IRR (Internal Rate of Return) di peroleh tingkat bunga sebesar $15,2 \%$.

e) Metode PI (Profitabilitas Indeks) menunjukkan hasil yang di peroleh sebesar 1,10.

Berdasarkan hasil penilaian dengan 5 metode penilaian kelayakan investasi memberikan hasil yang positif bagi perkembangan investasi peralatan radiologi di RSU Rajawali Citra. 
B. Saran

Berdasarkan penelitian, saran-saran yang dapat disimpulkan sebagai berikut:

1) Bagi pihak rumah sakit rencana pengembangan investasi peralatan radiologi layak untuk dilakukan, dan sebaiknya pengembangan peralatan nantinya ke arah peningkatan jenis pemeriksaan dan peningkatan kapasitas peralatan yang sudah ada.

2) Seiring dengan persaingan pelayanan kesehatan yang sangat ketat,di harapkan RSU Rajawali Citra tetap mempertahankan tren positif terhadap kepuasan pelanggan mengenai pelayanan kesehatan yang telah diberikan.

3) Pengembangan radiologi nantinya juga diharapkan perbaikan sarana fisik ruangan radiologi baik mengenai standar luas bangunan dan perlengkapan didalamnya

\section{DAFTAR PUSTAKA}

1. Sugiharto, Toto, Studi Kelayakan Proyek Pengembangan Perkebunan Pisang Abaca dengan Menggunakan Analisis Penganggaran Modal, Jurnal Ekonomi Dan Bisnis, Jilid 7, No 3;145-150. 2002

2. Halim, Abdul, Analisis Investasi, Halaman 4 - 5, Salemba Empat, Jakarta. 2005 